\title{
Fast and efficient integrated silicon PIN-finger photodetector from ultraviolet up to near infrared
}

\author{
A. Nemecek, K. Oberhauser, G. Zach, and H. Zimmermann, Senior Member, IEEE \\ Institute of Electrical Measurements and Circuit Design, Vienna University of Technology \\ Gusshausstrasse 25/354, 1040 Vienna, Austria \\ e-mail: alexander.nemecek@tuwien.ac.at, klaus.oberhauser@tuwien.ac.at, gerald.zach@tuwien.ac.at, and horst.zimmermann@ieee.org
}

\begin{abstract}
Results of an integrated silicon PIN-photodetector with structured anode fingers are presented. As an improvement to homogenous photodiodes, a structured detector for the visible range with anode fingers is shown. A PIN-design was realized to speed up the detector, avoiding slow carrier diffusion: the $\mathbf{p}^{+}$ doped finger-anode is arranged in a thick $\mathrm{n}^{-}$low doped intrinsic region placed inside an $\mathrm{n}^{+}$doped region. Due to this setup and a thick intrinsic region, a responsivity of $R=0.25 \mathrm{~A} / \mathrm{W}(0.43 \mathrm{~A} / \mathrm{W})$ at a wavelength of $410 \mathrm{~nm}(660 \mathrm{~nm})$ could be reached. The achieved bandwidth of the detector in the visible range is up to $3 \mathrm{GHz}$. The photodiode was realized in a modified $0.5 \mu \mathrm{m}$ BiCMOS process.
\end{abstract}

Index Terms-integrated optoelectronics, photodetectors, PINtechnology.

\section{INTRODUCTION}

$\mathrm{O}$ PTOelectronic integrated circuits (OEICs) are used for several optoelectronic applications like optical storage systems CD, DVD and blue-ray DVD; optical communication networks at $1.3 \mu \mathrm{m}$ and $1.5 \mu \mathrm{m}$. But also the market for optical networks in the visible range is growing, like plastic optical fiber (POF) e.g. networks in the automotive sector, and like optical interconnects. The demand on optical receivers for enhanced data rates together with high responsivity is therefore underlined.

The implementation of the whole data receiver in one technology as a system on chip (SOC), containing the photodetector together with e.g. a transimpedance amplifier circuit, features a lot of benefits compared to a separate design: avoiding electrical chip interconnections between the diode and the circuit means no bond wires or pads, that would represent a risk of peaking or a bandwidth limitation due to additional inductance and capacitance, respectively. Furthermore handling and packaging of the chip is also eased.

The design of a photodetector that is both - fast and efficient - requires a special setup of the diode. At first the photogenerated charge carrier motion should be dominated by drift. Light penetrating into regions without (or with weak) electric field causes slow diffusion. This can be avoided by the integration of a low doped intrinsic region, wherein the main part of electron-hole-pairs is accelerated by the electrical field strength. This means that the intrinsic region has to possess a

Manuscript received May 20, 2005. minimum width for sufficient absorption at a special wavelength. Fig. 1 illustrates the absorption coefficient for common semiconductor materials. For blue light charge carriers would recombine in a homogenous and high doped anode like in a conventional pin photodiode. Therefore drift is ensured also for shorter wavelengths by the structured finger design.

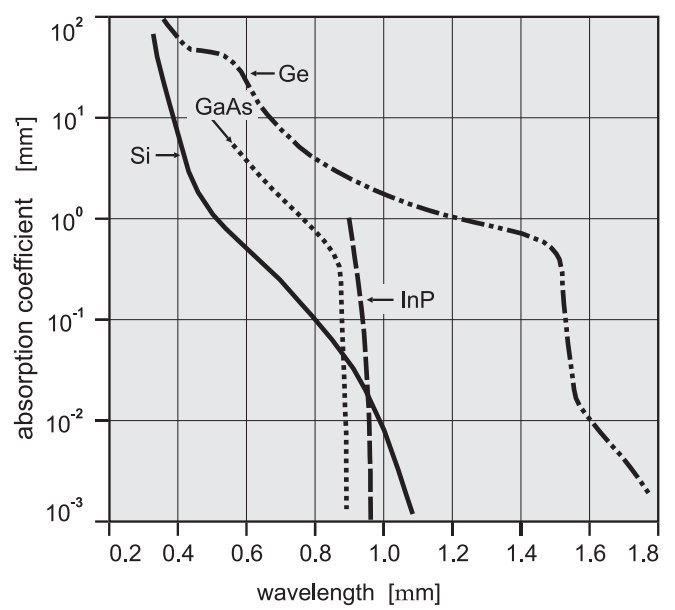

Figure 1: Absorption coefficient vs. wavelength of common semiconductor materials.

The absorption coefficient $\alpha$ defines the penetration depth $1 / \alpha$ of the incident optical power $P_{o p t}$ in the semiconductor material according to Lambert-Beer's law

$$
P(y)=P_{o p t} e^{-\alpha y}
$$

Ultraviolet light with $410 \mathrm{~nm}$ wavelength is absorbed to a very high extent in the $\mathrm{p}+$ anode where due to the high doping level, the carrier mobility and therefore the diffusion coefficient and the diffusion length are limited leading to a low quantum efficiency. The finger structure avoids this problem in the spacing between the $\mathrm{p}+$ fingers where the doping level is very low and fast carrier drift separates the photogenerated electron-hole pairs effectively leading to a much higher quantum efficiency for $410 \mathrm{~nm}$ than for a conventional pin photodiode.

In addition, the fundamental mechanism of speed enhancement by charge carrier separation in the electrical field, as described for the PIN-structure in fig. 2, occurs now also between the $\mathrm{p}^{+}$fingers. Generated electrons are directed 
to the $\mathrm{n}$ cathode, holes are lead to the $\mathrm{p}^{+}$finger anodes. Due to the drift force the presented detector was increased in its bandwidth. If we managed to generate all charge carriers in the drift region, presence of diffusion in the resulting photocurrent would be completely eliminated.

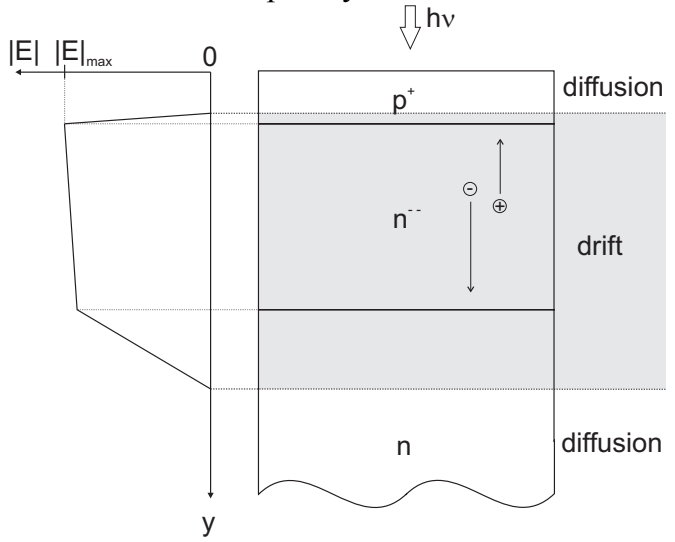

Figure 2: Charge carrier separation.

A fast photodetector based on a metall-semiconductormetall (MSM) structure on GaAs with a bandwidth $>39 \mathrm{GHz}$ was presented in [1]. The metal finger of the MSM structure, however, reduce the quantum efficiency. Another standardsilicon solution is presented in [2], where thanks to $\mathrm{SiO}_{2}$ and polysilicon a resonant-cavity structure with $\mathrm{f}_{3 \mathrm{~dB}}=10 \mathrm{GHz}$ was reported. Silicon avalanche photodiodes (APDs) [3] require very high reverse voltages for sufficient amplification and bandwidth. They are therefore only useful in integrated silicon circuits for blue light. Further silicon realizations of finger photodiodes are suggested in [4] on SOI and in [5] for CMOS, where rise and fall times of 1.0 and $1.1 \mathrm{~ns}$, respectively, were achieved.

\section{StRUCTURE OF THE Finger PHOtOdiode}

To isolate the photodiode from other components on the chip a $\mathrm{n}^{+}$-environment is established, consisting of the $\mathrm{n}^{+}$-buried layer and the $\mathrm{n}^{+}$-contacts from the surface (fig. 3) [6]. This kind of environment represents the cathode and encloses the $\mathrm{n}^{-}$-intrinsic region with low doping $<10^{14} \mathrm{~cm}^{-3}$. For achieving good performance with blue light the $\mathrm{p}^{+}$-anode is split up into small fingers. All $\mathrm{p}^{+}$-fingers are combined to a common anode.

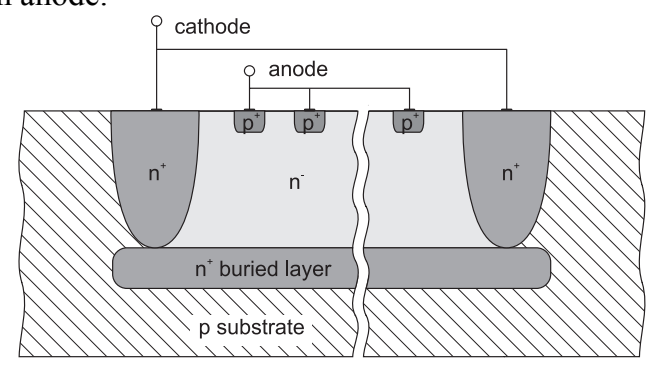

Figure 3: Cross-section of the finger-photodiode

Applying a reverse voltage to the electrodes the built-in electrical field increases, the space-charge region extends basically towards the substrate. Fig. 4 shows the potential exemplarily for $5 \mathrm{~V}$ reverse voltage as a result of simulations. As could be confirmed by measurements, higher bias voltages cause faster drift and therefore speed up the detector. Furthermore, the device simulator was used to optimize the finger dimensions and the distances between them. Finger photodiodes with a finger width of $0.6 \mu \mathrm{m}$ and a spacing of $5.1 \mu \mathrm{m}$ between the $\mathrm{p}^{+}$fingers were fabricated. The fingers were not metallized to increase the quantum efficiency. An anti-reflection coating is present on the photodiodes.

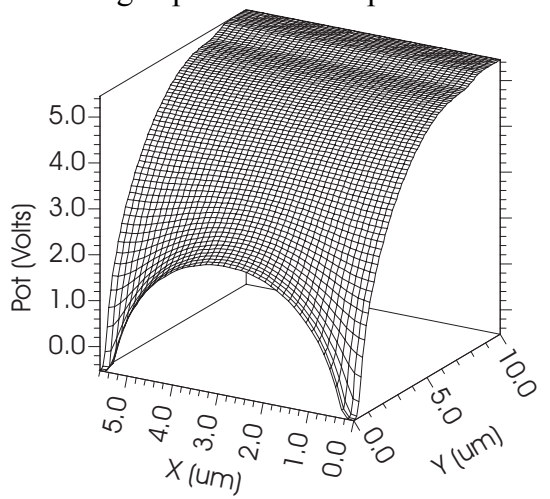

Figure 4: Simulated potential plot of the detector between two finger anodes at $V_{P D}=5 \mathrm{~V}$

\section{MEASUREMENT RESUltS}

For an ample device description several measurements were done: If reverse biased with the voltage $V_{P D}$, the photocurrent $i_{\text {opt }}$ results out of the incident optical power $P_{\text {opt }}$ and was measured at a $50 \Omega$ resistance to determine its responsivity. Values of $0.25 \mathrm{~A} / \mathrm{W}, 0.43 \mathrm{~A} / \mathrm{W}$, and $0.27 \mathrm{~A} / \mathrm{W}$ were determined for wavelengths of $410 \mathrm{~nm}, 660 \mathrm{~nm}$, and $850 \mathrm{~nm}$, respectively, with the help of an optical power meter. Compared to first silicon results with a bandwidth of $500 \mathrm{MHz}$ at $660 \mathrm{~nm}$ [7], the responsivity is improved by $\sim 20-50 \%$. The capacitance $C_{P D}$, which is important for circuit bandwidth, is reduced with increasing reverse bias voltage, until the space charge region (SCR) is fully expanded. Due to the finger setup, mainly edge capacitance is dominating. Fig. 5 shows $C_{P D}$ for the two realized diodes: with dimensions of $50 \mu \mathrm{m}$ and $100 \mu \mathrm{m}$ in square.

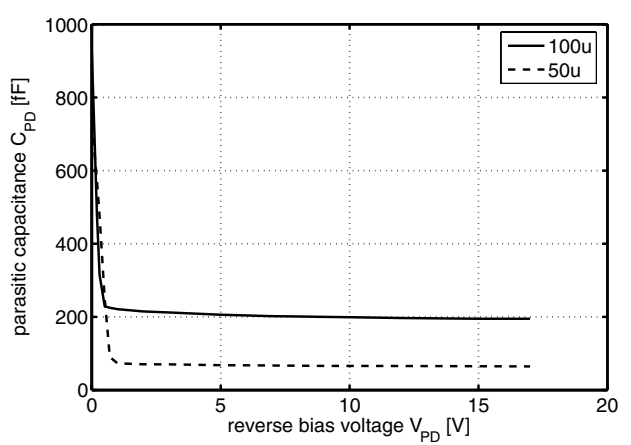

Figure 5: Measured parasitic photodiode capacitance of photodiodes in dimension $50 \mu \mathrm{m}$ and $100 \mu \mathrm{m}$ vs. reverse bias voltage $V_{P D}$. 


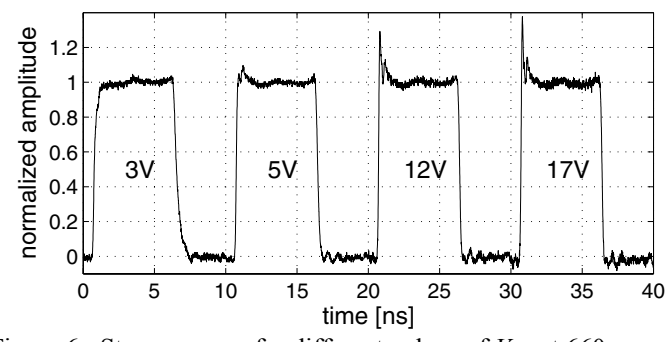

Figure 6: Step response for different values of $V_{P D}$ at $660 \mathrm{~nm}$.

Moreover the transient step response is measured for different values of $V_{P D}$ and different wavelengths. As can be seen from Fig. 6 and table 1 the rise time (10\%-90\%) and fall time $(90 \%-10 \%)$ increases also with $V_{P D}$ as a result of the higher drift field. The increasing speed of the photodiode with increasing reverse bias in Fig. 6 reveals the overshoot of the laser diode starting from about $12 \mathrm{~V}$. This overshoot of the laser diode, however, is also present for $3 \mathrm{~V}$ and $5 \mathrm{~V}$. Variations between simulated and measured values occur because of the approximated doping profile and the non ideal laser sources. This effect of laser overshoot reduces especially the measured rise time for $660 \mathrm{~nm}$ (for "switching off" the laser there is no overshoot). The true photodiode rise time therefore is longer than the measured one. The measured bandwidth at a wavelength of $410 \mathrm{~nm}, 660 \mathrm{~nm}$ and $850 \mathrm{~nm}$ is shown in fig. 7 . The large deviation between measured and simulated rise and fall times at $410 \mathrm{~nm}$, possibly is due to effects at the silicon/silicon dioxide interface due to positive oxide charges increasing the electron concentration in the spaces between the $\mathrm{p}^{+}$fingers close to the oxide. Partial reduction or screening of the electric field therefore may be present in these regions leading to a reduced drift speed. Segregation of dopants could be another explanation leading to the same effect of speed reduction. For red and near infrared light, these effects are not as severe because most of carriers are generated deeper in the silicon.

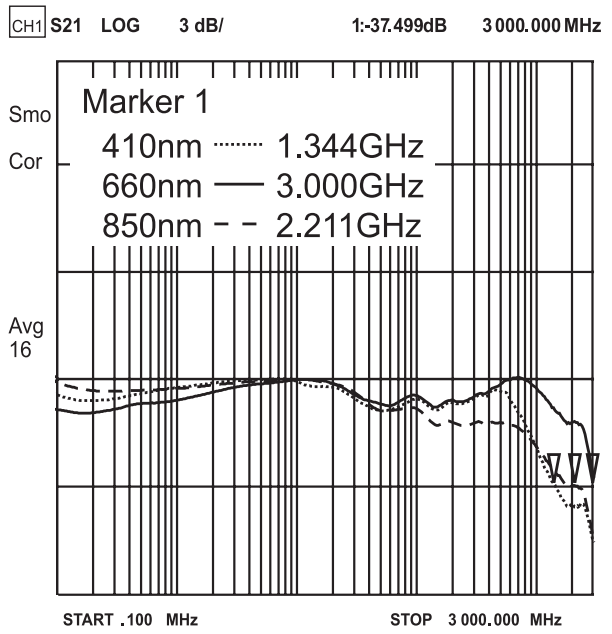

Figure 7: Frequency response of the photodetector at $V_{P D}=17 \mathrm{~V}$
TABLE I

PHOTODETECTOR CHARACTERISTICS

\begin{tabular}{|c|c|c|c|c|c|}
\hline & \multicolumn{2}{|c|}{ Simulation } & \multicolumn{3}{|c|}{ Measurement } \\
\hline $\begin{array}{l}\text { voltage } \\
V_{P I N}[\mathrm{~V}]\end{array}$ & $\begin{array}{c}\text { rise time } \\
t_{\text {rise }}[\mathrm{ps}]\end{array}$ & $\begin{array}{c}\text { fall time } \\
t_{\text {fall }}[\mathrm{ps}]\end{array}$ & $\begin{array}{l}\text { bandwidth } \\
f_{3 d B}[\mathrm{MHz}]\end{array}$ & $\begin{array}{c}\text { rise time } \\
t_{\text {rise }}[\mathrm{ps}]\end{array}$ & $\begin{array}{c}\text { fall time } \\
t_{\text {fall }}[\mathrm{ps}]\end{array}$ \\
\hline \multicolumn{6}{|l|}{$\lambda=410 \mathrm{~nm}$} \\
\hline 3 & 252 & 197 & - & 2500 & 2150 \\
\hline 5 & 202 & 163 & - & 930 & 1100 \\
\hline 12 & 125 & 108 & - & 204 & 263 \\
\hline 17 & 116 & 98 & $1344^{*}$ & 228 & 211 \\
\hline \multicolumn{6}{|l|}{$\lambda=660 \mathrm{~nm}$} \\
\hline 3 & 827 & 834 & 255 & 258 & 556 \\
\hline 5 & 370 & 320 & 709 & 132 & 274 \\
\hline 12 & 170 & 142 & 2243 & 84 & 200 \\
\hline 17 & 140 & 126 & $3000^{+}$ & 88 & 187 \\
\hline \multicolumn{6}{|l|}{$\lambda=850 \mathrm{~nm}$} \\
\hline 3 & 2334 & 2345 & 88 & 2540 & 2620 \\
\hline 5 & 765 & 742 & 256 & 703 & 1016 \\
\hline 12 & 285 & 242 & 1847 & 350 & 357 \\
\hline 17 & 247 & 205 & 2211 & 285 & 215 \\
\hline
\end{tabular}

* limited due to available laser source bandwidth.

${ }^{+}$maximal bandwidth range of the network analyzer reached.

\section{CONCLUSION}

Due to the structured finger anodes and the thick intrinsic region a wide spectral range from $410 \mathrm{~nm}$ to $850 \mathrm{~nm}$ is covered at both, high bandwidth and high efficiency. This all silicon detector can be implemented together with analog and/or digital circuitry on chip. Therefore, this detector will enable cheap data receivers in widely available pure silicon technology with enhanced data rates up to at least $5 \mathrm{~Gb} / \mathrm{s}$ for optical interconnects. This leads together with high sensitivity also in the visible range, necessary for e.g. POF networks or data storage media, to a multipurpose photodetector.

\section{ACKNOWLEDGMENT}

The authors would like to thank R. Swoboda for his support in the design and measurements.

\section{REFERENCES}

[1] J. Burm, K.I. Litvin, D.W. Woodard, W.J. Schaff, P. Mandeville, M.A Jaspan, M.M. Gitin, and L.F. Eastman, "High-frequency, high-efficiency MSM photodetectors," IEEE Journal of Quantum Electronics, vol. 31, Iss. 8, pp. 1504-1509, 1995

[2] J.C. Bean, Qi Jieming, C.L. Schow, et al. "High-speed polysilicon resonant-cavity photodiode with $\mathrm{SiO} 2$-Si Bragg reflectors," IEEE Photonics Technology Letters, Vol. 9, Iss. 6, pp. 806-808, 1997

[3] T. Miyata, T. Araki, and T. Iwata, "Correction of the intensitydependent phase delay in a silicon avalanche photodiode by controlling its reverse bias voltage," IEEE Journal of Quantum Electronics, , Vol. 39, Iss. 7, pp. 919-923, 2003

[4] H. Zimmermann, and M. Muller, "Ultralow-capacitance lateral p-i-n photodiode in a thin c-Si film," IEEE Transactions on Nuclear Science, Vol. 49, Iss. 4, pp. 2032-2036, 2002

[5] A. Ghazi, H. Zimmermann, and P. Seegebrecht, "CMOS photodiode with enhanced responsivity for the UV/blue spectral range," IEEE Transactions on Electron Devices, vol. 49, Iss. 7, pp. 1124-1128, 2002

[6] M. Yamamoto, M. Kubo, K. Nakao, "Si-OEIC with a Built-In PINPhotodiode", IEEE Trans. Electron. Dev., Vol. 42, No. 1, pp. 58-63, 1995

[7] K. Oberhauser, A. Nemecek, Ch. Sünder, and H. Zimmermann, "Universal Integrated PIN Photodetector," 34th European Solid-State Device Research Conference ESSDERC, pp. 349-352, 2004. 